\title{
Erratum to: An unusual congenital anomaly in the pulmonary artery and vein of a Holstein calf
}

\author{
A. Jafari Dehkordi • R. A. Fatahian Dehkordi • \\ A. Borjan
}

Published online: 4 February 2010

(C) Springer-Verlag London Limited 2010

\section{Erratum to: Comp Clin Pathol DOI: $10.1007 / \mathrm{s} 00580-009-0930-8$}

The original version of this article unfortunately contained a mistake. The presentation of Figs. 4, 5 and 6 were incorrect. The corrected figures are given below.

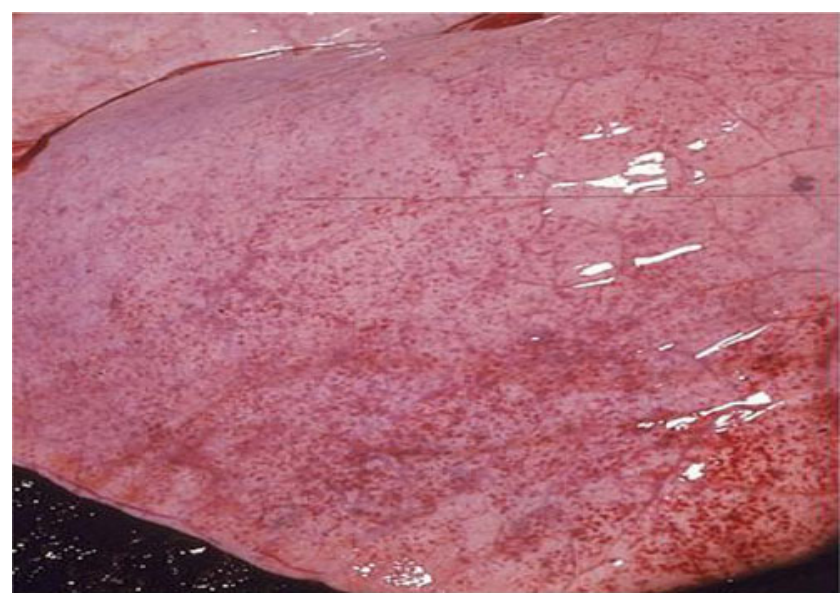

Fig. 4 Rubbery lung with ecchymotic and petechial hemorrhages

The online version of the original article can be found under http:/dx. doi.org/10.1007/s00580-009-0930-8.

\section{A. J. Dehkordi $(\square)$}

Department of Large Animal Internal Medicine,

Shahrekord University,

Shahrekord, Iran

e-mail: jafari-a@vet.sku.ac.ir

\section{R. A. F. Dehkordi}

Department of Veterinary Anatomy, Shahrekord University,

Shahrekord, Iran

\section{A. Borjan}

Shahrekord University,

Shahrekord, Iran

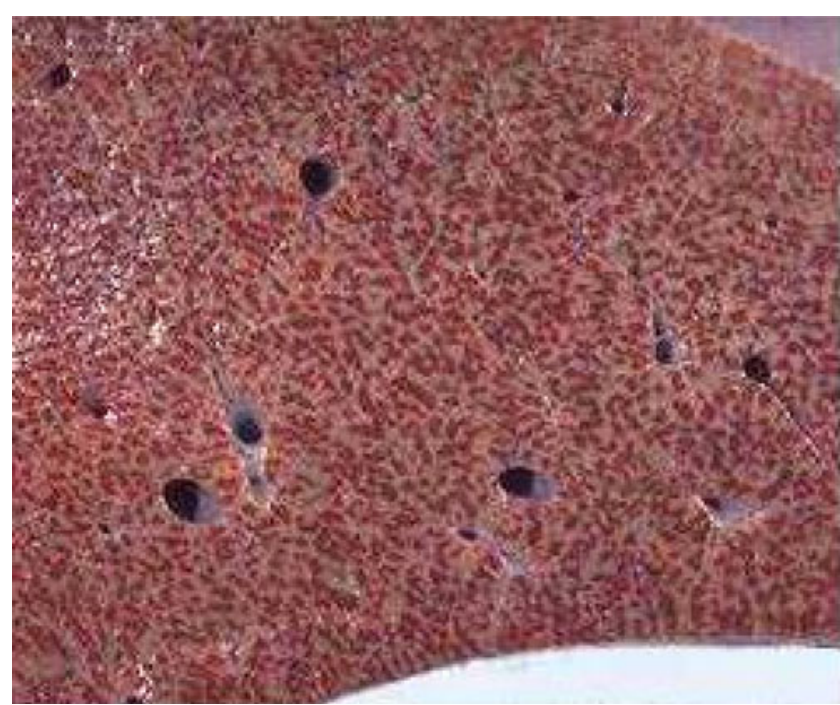

Fig. 5 Cut surface of the liver. Note accentuation of the normal lobular pattern

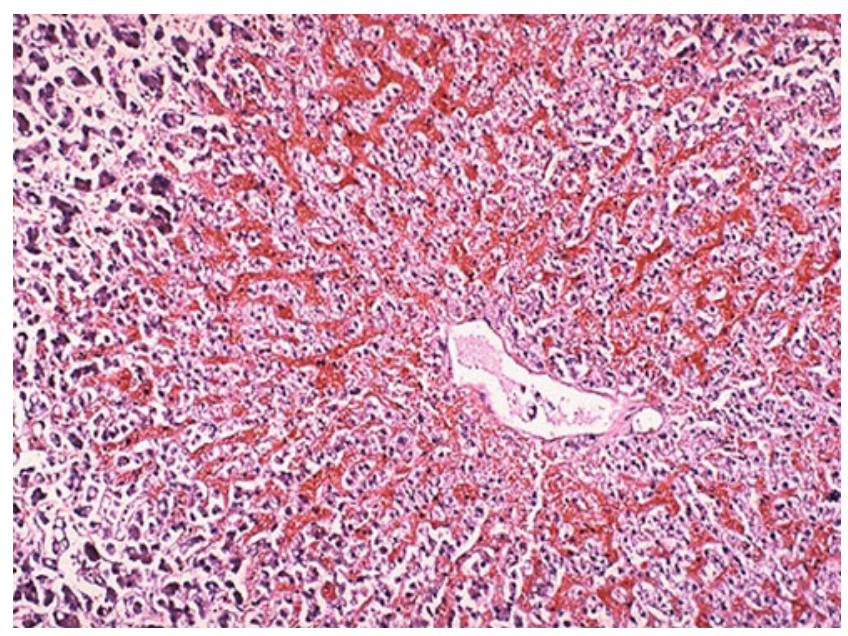

Fig. 6 Liver, accumulation of red blood cells around central vein and the absence of hepatocytes (hematoxylin and eosin) 